\title{
Mass Transfer to Amalgamated Copper Rotating Disk Electrode
}

\author{
Abbas H. Sulaymon ${ }^{\mathrm{a}}$ and Ali H. Abbar ${ }^{\mathrm{b}, \uparrow}$ \\ ${ }^{a}$ Environmental Engineering Department, Baghdad University, Iraq \\ ${ }^{b}$ Department of Chemical Engineering, Qadessyia University, Iraq
}

\begin{abstract}
:
An experimental study of mass transfer to an amalgamated copper rotating disc electrode has been employed to determine an empirical correlation for the mass transfer rate in laminar flow. The study was performed in a three-electrodes configuration using $0.1 \mathrm{M}$ boric acid and $0.1 \mathrm{M}$ potassium chloride as supporting electrolyte with $\mathrm{Zn}$ (II) concentration in the range $\left(25-100 \mathrm{mg} \mathrm{dm}^{-3}\right)$. Polarization curves at different zinc ion concentration are reported. Hydrogen and oxygen reduction has also been considered.The diffusion coefficients and mass transfer coefficient were obtained using limiting diffusion current technique based on zinc ion reduction. A least squares analysis indicates that the laminar flow results for $13067<\mathrm{Re}>57552$ and $550<\mathrm{Sc}>1390$ can be correlated by the following equation with correlation coefficient (CR) equal to 0.98 : $s h=0.61 \mathrm{Re}^{0.5} \mathrm{Sc}^{1 / 3}$
\end{abstract}

Keywords : Rotating disk electrode, Electrodepostion, Mass transfer, Zinc reduction, Amalgamated copper electrode

Received November 30, 2012: Accepted December 30, 2012

\section{Introduction}

The rotating disc electrode has been used for investigating the hydrodynamic, kinetics and mechanism of electrochemical reaction. The hydrodynamics and the mass-transfer characteristics are well understood and current density on the disc electrode is supposed to be uniform. However, the current distribution is uniform only at the limiting current where the concentration of the reactant is zero at the electrode surface. ${ }^{1)}$ Rotating disc electrodes (RDE) represent very practical systems for current-potential curve determination and the RDE, with precise limiting current behavior, probably is the most promising of all solid electrode systems. The rotating disc electrode solves many problems connected with the use of solid electrodes both from the experimental and theoretical point of view.

Electrochemical techniques, in particular masstransfer measurements by limiting-current method,

${ }^{\dagger}$ Corresponding author. Tel.: +964-78-0689-8052

E-mail address: aliha68@yahoo.com provide convenient and accurate means for the determination of local and average transport rates. Applying analogies between momentum, heat, and mass transport, electrochemical measurements provide insight into the fundamental aspects of transport which are convenient for obtaining transport-rate correlation. These are useful for design purposes in electrochemical system such as electrowining and electrochemical treatment of waste water. The limiting-current technique is based on driving an electrochemical reaction to its maximum possible rate where it is limited by mass transport. The limit is indicated by a current plateau" the limiting current" on a current-versus-potential plot. To calculate the limiting current $i_{L}$, Levich ${ }^{2)}$ has obtained the solution of the convective-diffusion equation for the rotating disc electrode by applying Von Karman's hydrodynamic theory assuming that within the diffusion layer, there is no convection, an approximation which means that the variations in the velocity components must occur within distance much greater than the diffusion layer thickness by at least a factor of 10 . This assumption should be verified for 
any hydrodynamic system under study. The solution of the convective-diffusion equation expressed in terms of limiting currents is: ${ }^{1)}$

$$
\mathrm{i}_{\mathrm{L}}=0.62 \mathrm{nFAD} \mathrm{D}^{2 / 3} v^{1 / 6} \omega^{1 / 2} \mathrm{C}_{\mathrm{b}}
$$

Equation (1) is called Levich equation in which the limiting current is proportioned to the square root of angular velocity (w). Diffusion coefficient (D) is determined from the slope of the curve of limiting current and $\mathrm{w}^{1 / 2}$.

The mass transfer coefficient $\left(\mathrm{k}_{\mathrm{m}}\right)$ is determined from the limiting current according to the following relation: ${ }^{3)}$

$$
\mathrm{k}_{\mathrm{m}}=\frac{\mathrm{i}_{\mathrm{L}}}{\mathrm{nFAC}_{\mathrm{b}}}
$$

For the purpose of comparison of different systems it is usual to apply dimensionless numbers such as the Sherwood number, Reynolds number and Schmidt number instead of mass transfer coefficient and superficial solution velocity. For rotating disc electrode, these dimensionless numbers are defined as follows:

$$
\mathrm{Sh}=\frac{{ }_{\mathrm{m}}{ }^{\mathrm{d}}}{\mathrm{D}} \quad \mathrm{Re}=\frac{\mathrm{r}^{2} \omega}{v} \quad \mathrm{Sc}=\frac{\mu}{\rho \mathrm{D}}
$$

Accordingly, mass transport data are correlated experimentally using the following dimensionless relationship valid for a great variety of electrolytic reactor designs: ${ }^{4)}$

$$
\mathrm{Sh}=\mathrm{cRe}^{\mathrm{m}} \mathrm{Sc}^{0.33}
$$

Many researchers have been dealt with hydrodynamic voltammetric experiment using rotating disc electrode to obtain mass transfer correlations by determining the limiting current and the range of potentials over which the reaction is controlled by mass transfer for different electrochemical systems. ${ }^{3-9)}$ Other researchers calculate the diffusion coefficient of metallic ions in a dilute solutions under the conditions of their experiments using Levich equation. ${ }^{3,6,8,10)}$

The measurements of mass transfer coefficients to rotating disc electrode have been investigated by several researchers using different electrode materials and reactions systems under laminar, transient and turbulent flows. ${ }^{11-16)}$ To best of our knowledge, the mass transfer on amalgamated rotating electrode is still in blank. In previous report diffusion coefficient of L- cystine hydrochloride was obtained using mercuryplated copper rotating disc electrode, however no mass transfer correlation is proposed in this work. ${ }^{17)}$

The aim of the present work is to study the mass transfer properties on amalgamated copper rotating disc electrode using $\mathrm{Zn}(\mathrm{II})$ reduction from chloride solution as test reaction. The diffusion coefficient of $\mathrm{Zn}$ (II) under mass transfer control is determined by Levich equation then mass transfer correlation is determined based on experimental data.

\section{Experimental}

All reagents used were of analytical grade. Solutions were prepared using distilled and deionized water. The $\mathrm{Zn}$ (II) solutions were prepared from $\mathrm{ZnCl}_{2}$ using $0.1 \mathrm{M}$ of boric acid and $0.1 \mathrm{M}$ of potassium chloride as supporting electrolyte with $\mathrm{Zn}$ (II) concentration $25-100 \mathrm{mg} \mathrm{dm}^{-3}$. The resulting solution presented pH 5.5. The physical properties of the electrolytic solutions used in the experiment are listed in Table 1. The concentration of Zn (II) was determined by atomic absorption technique. The atomic absorption standards were prepared from a titrisol standard solution (Merck).

The hydrodynamic voltammetric experiments were carried out in a conventional three-electrode cell using a model 273A potentiostat/galvanostat system from EG and G Princeton Applied Research Corporation. An amalgamated copper rotating disc electrode $\left(16.133 \mathrm{~cm}^{2}\right)$ was used as working electrode. A largesurface platinum counter-electrode, and a saturated calomel reference electrode (SCE) within a loggin capillary were used.

The reactions involved in this system are:

Cathodic reactions are:

- $\mathrm{Zn}^{+2}+2 \mathrm{e} \rightarrow \mathrm{Zn}$ main reaction (zinc deposition)

- $2 \mathrm{H}^{+}+2 \mathrm{e} \rightarrow \mathrm{H}^{2}$ side reaction (hydrogen evolution)

- $2 \mathrm{O}_{2}(\mathrm{~g})+4 \mathrm{H}^{+}+4 \mathrm{e} \rightarrow 2 \mathrm{H}_{2} \mathrm{O}_{2}$ side reaction (oxygen reduction)

Anodic reactions are:

- $2 \mathrm{Cl}^{-} \rightarrow \mathrm{Cl}_{2}+2 \mathrm{e}$ main reaction (chlorine evolution) 
Table 1. Physical properties of the electrolytic Zinc solutions

\begin{tabular}{ccc}
\hline $\begin{array}{c}\text { Zinc Concentration } \\
\left(\mathrm{mg} \mathrm{dm}^{-3}\right)\end{array}$ & $\begin{array}{c}\text { Density } \\
\left(\mathrm{g} \mathrm{cm}^{-3}\right)\end{array}$ & $\begin{array}{c}\text { Viscosity (kinematic) } \\
\left(10^{-2} \mathrm{~cm}^{2} \mathrm{~s}^{-1}\right)\end{array}$ \\
\hline 25 & 1.0058 & 0.8257 \\
50 & 1.0059 & 0.8271 \\
100 & 1.0063 & 0.8452 \\
\hline
\end{tabular}

- $2 \mathrm{H}_{2} \mathrm{O} \rightarrow \mathrm{O}_{2}+4 \mathrm{H}^{+}+2 \mathrm{e}$

auxiliary reaction (oxygen evolution)

The amalgamation of copper disc electrode was achieved by chemically depositing mercury from a $2 \%$ mercuric sulphate solution in 5\% sulphuric acid for 5 min. ${ }^{18)}$ The current-voltage curves were obtained in buffered $\mathrm{Zn}$ (II) solution ( $\mathrm{pH}$ 5.5) for different concentrations of zinc ion by linear scanning the working electrode potential between $(0.0 \mathrm{~V}$ and $-1.8 \mathrm{~V})$ at $\left(20 \mathrm{mV} \mathrm{s}^{-1}\right)$. All experiments were carried out at room temperature $(298 \mathrm{~K})$.

\section{Results and Disscusion}

Figs. 1-3 show the series of polarization curves at different rotation rates for different initial concentrations of $\mathrm{Zn}$ (II) solution. The limiting current was measured at the mid point of the plateau. The potential was scanned on amalgamated copper rotating disc electrode, using five different rotation rates $(400,800$, 1200, 1600, $2000 \mathrm{rpm}$ ). During Zn (II) reduction, hydrogen evolution is always a competitive parallel process. In the range of potential in which the reduction becomes mass transfer controlled, the reduction of oxygen and of chloride also contributes to the recorded current. All these reduction processes amplify the response apparently without changing its shape, taking this fact into account, a series of background voltammograms are recorded under the same conditions as those in Figs. 1-3, but without zinc. These background voltammograms are shown in Fig. 4. It can be seen that the limiting current increases with increasing rotation rate. This behavior is characteristic of a mass-transfer controlled process. ${ }^{19)}$ As shown in these figures the range of potential when the reduction of $\mathrm{Zn}(\mathrm{II})$ is mass transport controlled lies in the range $(-1.35 \mathrm{~V}$ to $-1.4 \mathrm{~V})$.

According to Greef et al. ${ }^{20)}$ the application of the Levich equation is an appropriate test to verify whether an electrode process is conducted under a mass-transfer controlled condition. The limiting currents measured at the mid point of the plateaus are plotted as a function of the square roots of rotation rates (I vs. $\omega^{1 / 2}$ ) for different initial concentrations of $\mathrm{Zn}$ (II) as shown in Figs. 5-7 which are called the total current lines. The background currents at a potential in which the reduction becomes mass transfer controlled also plotted in these figures. These values of back-

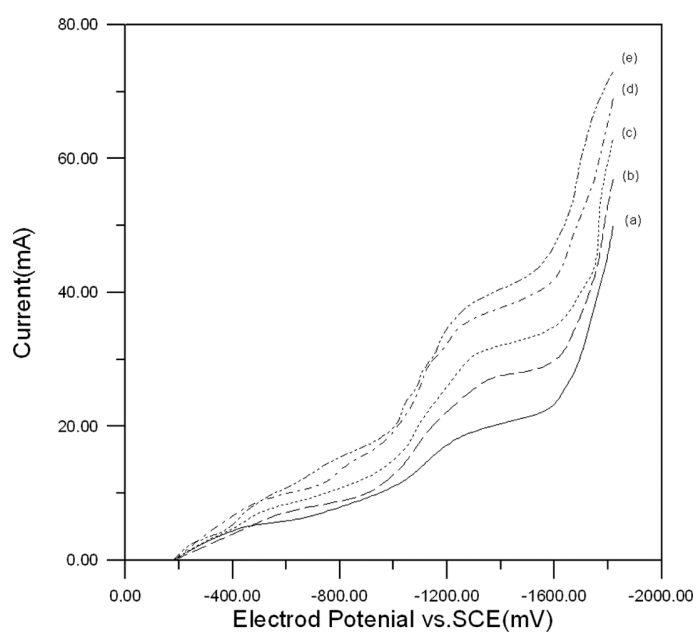

Fig. 1. Cathodic portions of voltammograms obtained with amalgamated copper rotating disc electrode: initial concentration of $\mathrm{Zn}$ (II) $25 \mathrm{mg} \mathrm{dm}^{-3}$. Rotation rate: (a) $400 \mathrm{rpm}$, (b) $800 \mathrm{rpm}$, (c) $1200 \mathrm{rpm}$, (d) $1600 \mathrm{rpm}$, (e) $2000 \mathrm{rpm}$.

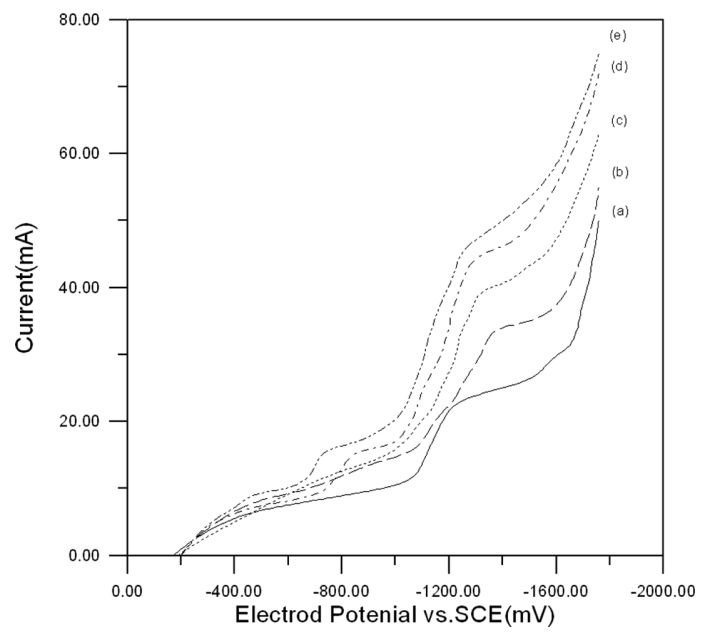

Fig. 2. Cathodic portions of voltammograms obtained with amalgamated copper rotating disc electrode: initial concentration of $\mathrm{Zn}$ (II) $50 \mathrm{mg} \mathrm{dm}^{-3}$. Rotation rate: (a) $400 \mathrm{rpm}$, (b) $800 \mathrm{rpm}$, (c) $1200 \mathrm{rpm}$, (d) $1600 \mathrm{rpm}$, (e) $2000 \mathrm{rpm}$. 


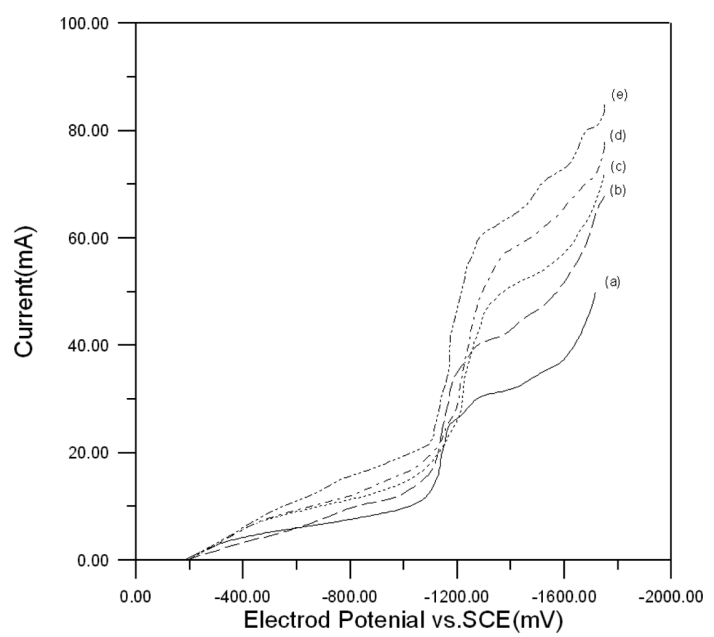

Fig. 3. Cathodic portions of voltammograms obtained with amalgamated copper rotating disc electrode: initial concentration of $\mathrm{Zn}$ (II) $100 \mathrm{mg} \mathrm{dm}^{-3}$. Rotation rate: (a) $400 \mathrm{rpm}$, (b) $800 \mathrm{rpm}$, (c) $1200 \mathrm{rpm}$, (d) $1600 \mathrm{rpm}$, (e) $2000 \mathrm{rpm}$.

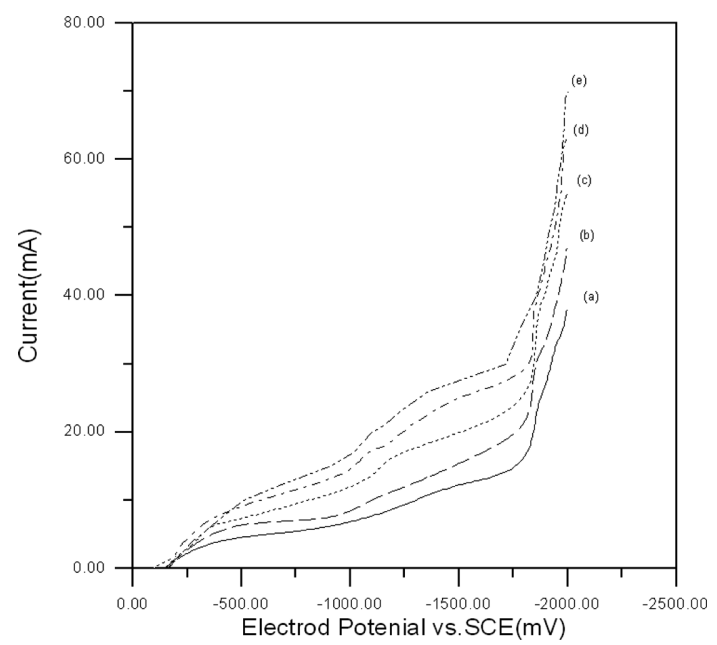

Fig. 4. Cathodic portions of voltammograms obtained with amalgamated copper rotating disc electrode without zinc. Rotation rate: (a) $400 \mathrm{rpm}$, (b) $800 \mathrm{rpm}$, (c) $1200 \mathrm{rpm}$, (d) $1600 \mathrm{rpm}$, (e) $2000 \mathrm{rpm}$.

ground currents are subtracted from total current for the same value of $\left(\omega^{1 / 2}\right)$ such that the resulting values are exclusive for zinc reduction current. As predicted by the Levich equation, the plots are linear, confirming the fact that under the conditions of this study, zinc deposition becomes mass-transport controlled at potentials more negative than $-1.2 \mathrm{~V}$ vs. SCE.

Data from the curves in Figs. 5-7 were used for the

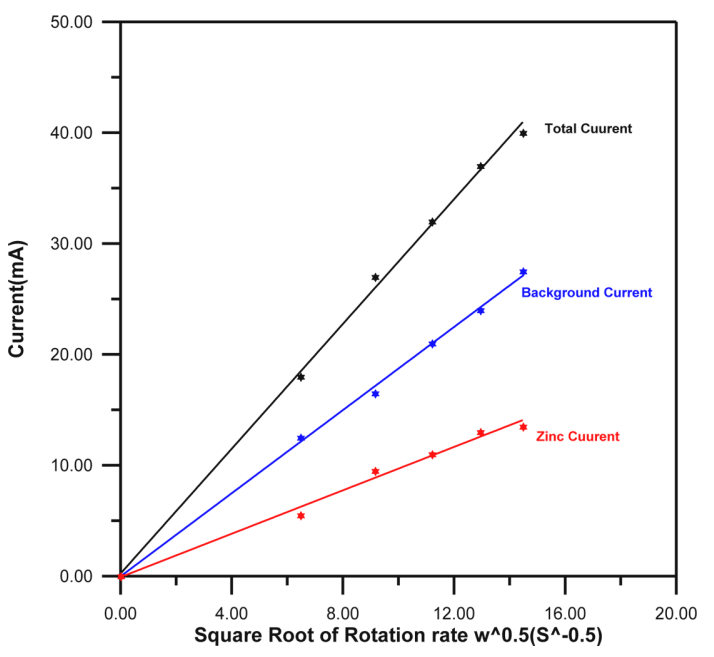

Fig. 5. Levich plots for the limiting currents taken at a potential of $-1.35 \mathrm{~V}$ vs. SCE: initial concentration of $\mathrm{Zn}$ (II) $25 \mathrm{mg} \mathrm{dm}^{-3}$.

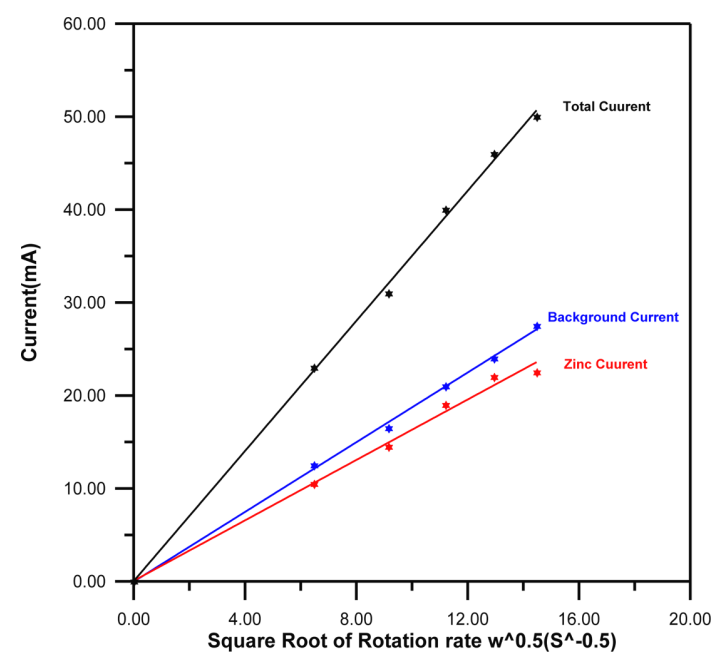

Fig. 6. Levich plots for the limiting currents taken at a potential of $-1.35 \mathrm{~V}$ vs. SCE: initial concentration of $\mathrm{Zn}$ (II) $50 \mathrm{mg} \mathrm{dm}^{-3}$.

estimation of diffusion coefficient (D) of $\mathrm{Zn}$ (II) in the chosen medium, provided the slope(s) in Levich's plot can be expressed as follows:

$$
\mathrm{s}=0.62 \mathrm{nAFD}{ }^{2 / 3} v^{-1 / 6} \mathrm{C}_{\mathrm{Zn}}
$$

Table 2 reports the diffusion coefficient for $\mathrm{Zn}$ (II) determined in this study at $298 \mathrm{~K}$. It can be seen from Table 2 that diffusion coefficient decreases with 


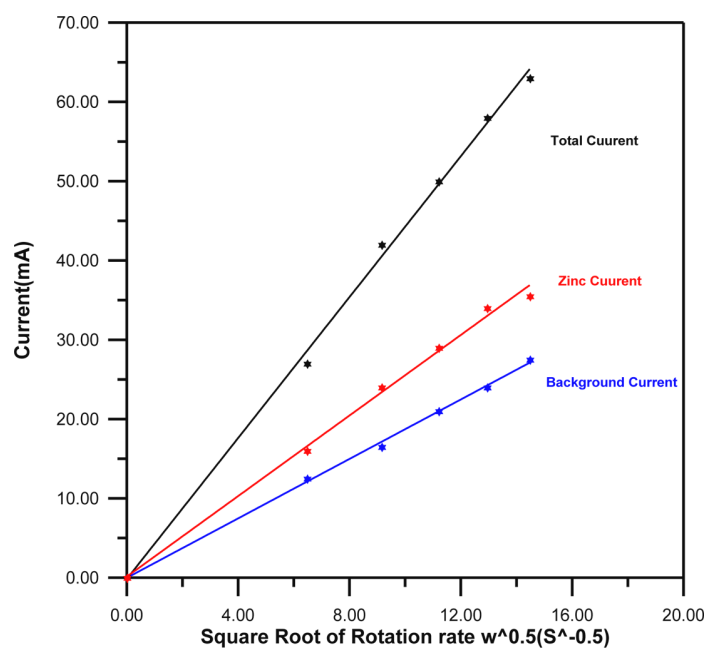

Fig. 7. Levich plots for the limiting currents taken at a potential of $-1.35 \mathrm{~V}$ vs. SCE: initial concentration of $\mathrm{Zn}$ (II) $100 \mathrm{mg} \mathrm{dm}^{-3}$.

Table 2. Diffusion coefficient for Zinc (II) in aqueous media at $298 \mathrm{~K}$.

\begin{tabular}{cc} 
boric acid $(0.1 \mathrm{M})+$ potassium chloride $(0.1 \mathrm{M}), \mathrm{pH} 5.5$ \\
\hline $\begin{array}{c}{\left[\mathrm{Zn}^{+2}\right]} \\
\left(\mathrm{mg} \mathrm{dm}^{-3}\right)\end{array}$ & $\begin{array}{c}\mathrm{D} \\
\left(10^{-5} \mathrm{~cm}^{2} \mathrm{~s}^{-1}\right)\end{array}$ \\
\hline 25 & 1.5 \\
50 & 1.18 \\
100 & 0.8155 \\
\hline
\end{tabular}

increasing the bulk concentration of $\mathrm{Zn}$ (II). Decreasing of diffusion coefficients with increasing the concentration of zinc ion has also been reported previously for different types of electrolyte. ${ }^{21-23)}$ the diffusion coefficient of $\mathrm{Zn}$ (II) in $0.05 \mathrm{M} \mathrm{ZnCl}_{2}+$ $1.0 \mathrm{M} \mathrm{KCl}$ was estimated by $\mathrm{Kim}$ and $\mathrm{Jacob}^{24)}$ to be $0.89 \times 10^{-5} \mathrm{~cm}^{2} \mathrm{~s}^{-1}$ which is consistent with the results of present work.

The Sherwood numbers estimated at different rotation rates for various zinc ion concentrations have been plotted against the Reynolds number as shown in Figs. 8-10.The data were fitted to obtain the following correlation applied for different initial zinc concentrations:

$$
\mathrm{Sh}=0.61 \mathrm{Re}^{0.5} \mathrm{Sc}^{1 / 3}
$$

For $13067<\operatorname{Re}<57552$ and $550<\mathrm{Sc}<1390$ with correlation coefficient (CR) equal to 0.98 .

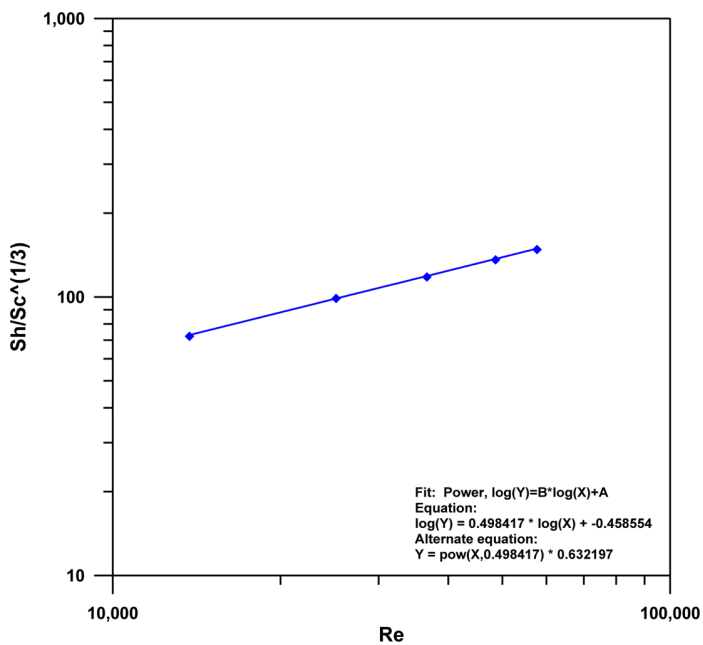

Fig. 8. Sherwood-Reynolds correlation for amalgamated copper rotating disc electrode at zinc concentration $25 \mathrm{mg}$ $\mathrm{dm}^{-3}$.

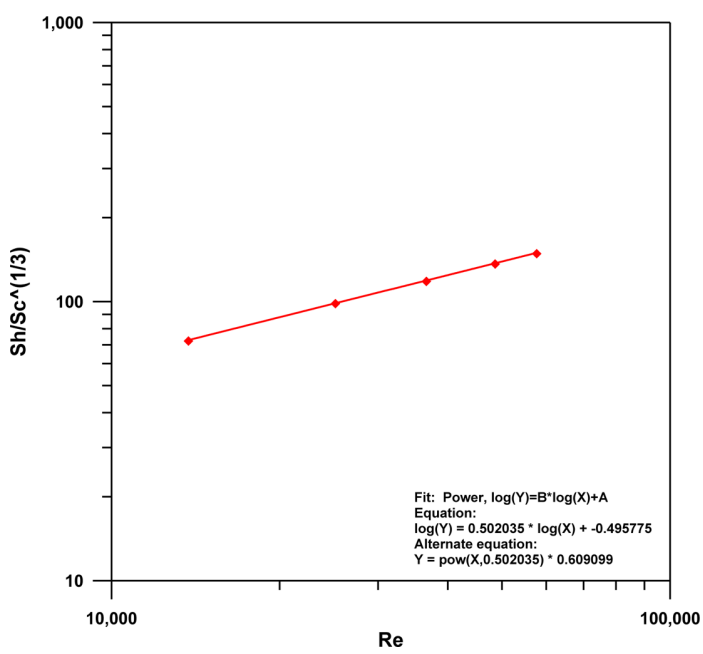

Fig. 9. Sherwood-Reynolds correlation for amalgamated copper rotating disc electrode at zinc concentration $50 \mathrm{mg}$ $\mathrm{dm}^{-3}$.

The mass transfer coefficient obtained by Lanza and Bertazzoli for zinc reduction on glassy carbon rotating disc electrode at $50 \mathrm{mgdm}^{-3}$ zinc ion concentration is lower than that obtained in the present work for the same conditions. ${ }^{25)}$ The reason may be the higher hydrogen overvoltage of amalgamated copper electrode which permits using higher current at the mass transfer control region. This characteristic of amalgamated copper electrode has been observed by several workers, especially in our previous research on 


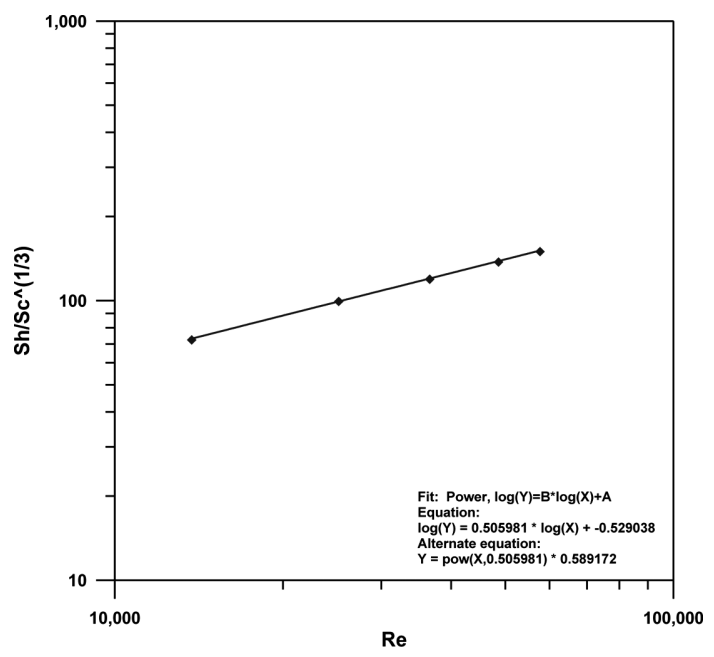

Fig. 10. Sherwood-Reynolds correlation for amalgamated copper rotating disc electrode at zinc concentration $100 \mathrm{mg}$ $\mathrm{dm}^{-3}$.

the reduction of nitrobenzene using this electrode. ${ }^{26)}$

The value of Reynolds number in the present work is lower than $10^{5}$ which emphasis the laminar flow condition. The transition from laminar to turbulent occurred at $\operatorname{Re}=3.0 \times 105$. $^{11)}$ The power of Reynolds No. in the present work is consistent with that obtained by Dib et al. ${ }^{16)}$ where the mass transfer correlation for simultaneous cementation of nickel and cobalt at glassy carbon rotating disk electrode in laminar flow condition is represented by the following correlation: $\mathrm{Sh}=1.43 \mathrm{Re}^{0.49} \mathrm{Sc}^{0.33}$

\section{Conclusions}

It is concluded that zinc deposition from chloride solution is an interesting test reduction reaction for mass transfer study on amalgamated copper rotating disk electrode because it has higher hydrogen overvoltage and shows a wide range of potential where the limiting current sustained. The voltammetry and hydrodynamic conditions used in the present work give diffusion coefficient for $\mathrm{Zn}$ (II) in the range $\left(0.815-1.5 \times 10^{-5} \mathrm{~cm}^{2} \mathrm{~s}^{-1}\right)$ which is in agreement with previous works.

The mass transfer on this type of electrode is well correlated by a dimensionless equation involving the Sherwood and Reynolds numbers in term of disk radius. The results indicate that the mass transfer coefficient is approximately constant over the range of ini- tial zinc ion concentration studied.

\section{Acknowledgements}

The authors are grateful to laboratories of Chemical Engineering Department/Technology University, Iraq and Ibn Sina laboratories for the facilities to perform the spectrophotometer analysis and utilizing the available equipments.

\section{NOTATION}

\begin{tabular}{|c|c|}
\hline A & Surface area of electrode, $\mathrm{cm}^{2}$ \\
\hline $\mathrm{C}_{\mathrm{b}}$ & Bulk Concentration, $\mathrm{mg} \mathrm{dm}^{-3}$ \\
\hline $\mathrm{c}$ & Constant in mass transfer correlation \\
\hline $\mathrm{D}$ & Diffusion coefficient, $\mathrm{cm}^{2} \mathrm{~s}^{-1}$ \\
\hline $\mathrm{d}$ & Diameter of disc, $\mathrm{cm}$ \\
\hline $\mathrm{F}$ & Faraday's constant $(96,485), \mathrm{C} \mathrm{mol}^{-1}$ \\
\hline $\mathrm{i}_{\mathrm{L}}$ & Limiting current, $\mathrm{mA}$ \\
\hline $\mathrm{k}_{\mathrm{m}}$ & Mass transfer coefficient, $\mathrm{cm} \mathrm{s}^{-1}$ \\
\hline $\mathrm{m}$ & Exponent of Reynolds number (Dimensionless) \\
\hline $\mathrm{n}$ & $\begin{array}{l}\text { Number of electrons transferred in the reaction } \\
\text { (Dimensionless) }\end{array}$ \\
\hline $\operatorname{Re}$ & Reynolds number, dimensionless, $\mathrm{r}^{2} \omega / \mathrm{v}$ \\
\hline $\mathrm{r}$ & Radius of disc, $\mathrm{cm}$ \\
\hline $\mathrm{Sh}$ & Sherwood number dimensionless, $\mathrm{k}_{\mathrm{m}} \mathrm{d} / \mathrm{D}$ \\
\hline $\mathrm{Sc}$ & Schmidt number dimensionless, $\mu / \rho D$ \\
\hline $\mathrm{s}$ & Levich slope (dimensionless) \\
\hline$\rho$ & Fluid density, $\mathrm{g} \mathrm{cm}^{-3}$ \\
\hline$\mu$ & Viscosity of fluid, $\mathrm{g} \mathrm{cm}^{-1} \mathrm{~s}^{-1}$ \\
\hline$v$ & Kinematic viscosity $(\mu / \rho), \mathrm{cm}^{2} \mathrm{~s}^{-1}$ \\
\hline$\omega$ & Rotation rate, $\operatorname{rad~s}^{-1}$ \\
\hline
\end{tabular}

\section{References}

1. C. M. A. Brett, Electrochemistry Principles, Methods and Applications, Oxford Science Publication (2002).

2. V. G. Levich, Physicochemical Hydrodynamics, Prentic Hall, Englewood Cliffs, New Jersy (1962).

3. D. Pletcher, I. Whyte, F. C. Walsh and J. P. Millington, J. Appl. Electrochem., 21, 659 (1991).

4. K. Rajesshwar and J. G. Ibanez, Environmental Electrochemistry: fundamentals and Applications in Pollution Sensors and Pollutant Treatment, Academic Press, San Diego (1997). 
5. R. Bertazzoli, R. C. Widner, M. R. V. Lanza, R. A. D. Iglia and M. F. B Sousa, J. Braz. Chem. Soc., 8, 487 (1997).

6. R. C. Widner, M. F. B. Sousa and R. Bertazzoli, J. Appl. Electrochem., 28, 201 (1998).

7. R. Bertazzoli, C. A. Rodrigues, E. J. Dakan, M. T. Fukunaga, M. R. V. Lanza, R. R. Leme and R. C. Winder, Braz. J. Chem. Eng., 15, 396 (1998).

8. A. R. Ragninic, R. A. DI Iglia, W. Bizzo and R. Bertazzoli, Water Res., 34, 3269 (2000).

9. M. R. V. Lanza and R. Bertazzoli, J. Appl. Electrochem., 30, 61 (2000).

10. M. Matlosz and J. Newman, J. Electrochem. Soc., 133, 1850 (1986).

11. J. Ellison and I. corent, J. Electrochem. Soc., 118, 68-72 (1971).

12. M. Charles, J. Moher and J. Newman, J. Electrochem. Soc., 123, 1687-1691 (1976).

13. O. T. Hanna, O. C. Sandall and G. Ruiz-Ibanez, Chem. Eng. Sci., 43, 1410-1407 (1988).

14. S.-C. Yen, J.-S. Wang and T. W. Chapman, J. Electrochem. Soc., 139, 2231-2238 (1992).

15. E. O. Cobo and J. B. Bessone, J. Appl. Electrochem., 28,
803-809 (1998).

16. L. Makhloufi, Chem. Eng. J., 130, 39-44 (2007).

17. T. R. Ralph, M. L. Hitchman, J. P. Millington and F. C. Walsh, Electrochimica Acta., 51, 133-145 (2005).

18. H. V. K. Udupa and N. Nagendra, The Society of Advancement of Electrochemical Science and Technology, New Delhi, 404 (1988).

19. R. N. Adams, Electrochemistry at Solid Electrodes, Edited by J. B. Allen (1969).

20. R. Greef, R. Peat, L. M. Peter and D. Pletcher, In Instrumental Methods in Electrochemistry, Chichester, Ellis Horwood (1990).

21. J. Leffler and H. T. Cullinan, Ind. Eng. Chem. Fundam., 9, 88-93 (1970).

22. A. R. Gordon, J. Chem. Phys., 5, 52 (1937).

23. V. G. Gurjar and I. M. Sharma, J. Appl. Electrochem., 19, $1113(1989)$

24. J. T Kim and J. Jacob, J. Electrochem. Soc., 127, 8-15 (1980).

25. M. R. V. Lanze and R. Bertazzoli, J. Appl. Electrochem., 30, 61-70 (2000).

26. A. H. Abbar and A. H. Sulaymon, Electrochim. Acta, 53, 1671-1679 (2007). 